\title{
SOBRE A POSSIBILIDADE DE DIÁLOGOS INSTITUCIONAIS ENTRE CORTES INTERNACIONAIS DE DIREITOS HUMANOS E NAÇÕES SOBERANAS
}

\author{
Henrique de Almeida Freire Gonçalves ${ }^{107}$
}

Recebido em: 19/11/2018

Aprovado em: 29/03/2019

\begin{abstract}
RESUMO
O presente artigo analisa os chamados "diálogos institucionais" e verifica possibilidade de ser aplicado por analogia na relação entre Cortes Internacionais e Estados Soberanos. Procura-se identificar problemas na jurisdição internacional de direitos humanos que poderiam ser enfrentados pela via do diálogo e identificar possibilidades de diálogo na aplicação de mecanismos já existentes nos sistemas regionais.
\end{abstract}

Palavras-chave: Diálogos Institucionais. Direito Internacional dos Direitos Humanos. Supranacionalidade.

\section{INTRODUÇÃO}

Um dos maiores problemas enfrentados na jurisdição internacional de direitos humanos, sobretudo no sistema interamericano, é a relativa inefetividade de suas decisões. Analisando o caso brasileiro, Diogo Pignataro de Oliveira (PIGNATARO DE OLIVEIRA, 2013, p. 12) conclui pela "completa ausência de tratamento legal e constitucional no âmbito interno" em relação à conferência de efetividade às sentenças internacionais.

Adotando recorte bem específico, mas que ilustra a inefetividade das decisões da Corte Interamericana de Direitos Humanos, Técio de Aguiar Rodrigues (RODRIGUES, 2014, p. 62) indica que apenas $16.67 \%$ das decisões da Corte foram cumpridas quando o assunto é o direito à propriedade coletiva de comunidades indígenas e tribais.

Essa relativa inefetividade contrasta com a tendência observada por Ran Hirschl (HIRSCHL, 2004, p. 1), de reformas transferindo uma quantidade sem precedentes de poder de instituições representativas para os judiciários pelas entidades supranacionais. Por um lado,

\footnotetext{
${ }^{107}$ Mestrando em Direito pelo Centro Universitário Autônomo do Brasil - UNIBRASIL. Especialista em Direito pela Universidade Veiga de Almeida - UVA/RJ.
} 
cada vez mais se caminha para a transferência de poder às Cortes Internacionais; por outro, o cumprimento às sentenças internacionais de direitos humanos no sistema interamericano deixa a desejar.

Abertura, cooperação e integração podem ser consideradas como elementos de uma nova estatalidade (MALISKA, 2006, p. 1). O recorrente descaso com que se trata a jurisdição da Corte Interamericana de Direitos Humanos é um obstáculo à integração supranacional que, pelo menos no caso brasileiro, parece ser constitucionalmente desejada (art. $4^{\circ}$, parágrafo único da CRFB).

A tensão entre constitucionalismo e democracia no plano interno é análoga a uma tensão entre imperatividade das decisões das cortes internacionais e a soberania e autodeterminação dos povos. Esta analogia entre o plano interno e internacional tem inspiração no pensamento de John Rawls: da mesma forma que no plano interno a Constituição decorre de um consenso sobreposto entre os indivíduos, o direito internacional decorre de um consenso sobreposto entre nações, ou, como prefere Rawls, o direito dos povos decorre de um consenso sobreposto entre os povos, que gera uma razão pública para a Sociedade dos Povos análoga à ideia de razão pública no caso interno (RAWLS, 2014, p. 25).

Também identificando similaridades entre a organização internacional e a ordem interna, Hans Kelsen, conforme citado por Marcos Augusto Maliska (MALISKA, 2003, p. 85), assinala que a Liga das Nações pode lembrar um estado federal em muitos aspectos.

Nessa linha, pode-se traçar um paralelo entre a relação entre as cortes internacionais e as nações soberanas no plano internacional e entre o poder judiciário e poder legislativo no plano interno. Saliente-se que ao traçar estes paralelos, não se quer aqui caracterizar tratados internacionais de direitos humanos como um "direito internacional paraconstitucional", ideia que mereceu pertinente crítica de Peter Haberle (HABERLE, 2007).

A fim de oferecer uma possível saída à tensão entre constitucionalismo e democracia, alguns atores defendem os chamados "diálogos institucionais" - uma alternativa tanto à supremacia judicial quanto à supremacia do parlamento. Tais poderes, de modo dialógico, construiriam uma interpretação da Constituição em conjunto, de modo a conferir maior legitimidade democrática ao controle de constitucionalidade. Foge-se do chamado "viés juriscêntrico", pertinente expressão utilizada por Rodrigo Brandão (BRANDÃO, 2017, p. 209).

Da mesma maneira, cogita-se a possibilidade de se adotar essa mesma solução para a tensão entre a imperatividade das decisões das cortes internacionais, com a efetiva proteção dos direitos humanos, e a soberania, com a autodeterminação dos povos. 
Embora o controle de convencionalidade também possa e deva ser exercido pelos judiciários locais, parece fora de dúvida que as cortes internacionais de direitos humanos também exercem controle de convencionalidade (HITTERS, 2009).

É nesse sentido que surge o problema desta pesquisa, ou seja, é possível e desejável a aplicação dos diálogos institucionais, mutatis mutandis, na relação entre cortes internacionais e nações soberanas?

A aplicação proposta se prestaria para tentar solucionar os principais problemas do controle de convencionalidade pelas cortes internacionais: de um lado, as possíveis alegações de violação de soberania e autodeterminação dos povos; de outro, a pouca efetividade verificada nas decisões destas cortes.

No desenvolvimento do presente trabalho foi utilizado o método de abordagem dedutivo, com adoção do procedimento monográfico e as técnicas de pesquisa bibliográfica e documental.

A pesquisa se desenvolve em duas partes: a primeira apresenta um apanhado do que é chamado de "diálogos institucionais" pela doutrina constitucionalista e a possibilidade de sua aplicação analógica à relação entre cortes internacionais e Estados soberanos; a segunda analisa possíveis instrumentos já existentes nos sistemas regionais como possíveis mecanismos indutores de diálogo.

\section{UM BREVE RESUMO SOBRE O QUE SE ENTENDE POR "DIÁLOGOS INSTITUCIONAIS" E A SUA ADAPTAÇÃO AO CASO INTERNACIONAL}

Como explica Sérgio Antônio Ferreira Victor (VICTOR, 2015, pp. 185 e seguintes), a Constituição do Canadá de 1982 instituiu modelo que evitava o monólogo judicial sobre a Constituição, como ocorria nos Estados Unidos. Tal modelo, em tese, viabilizaria o diálogo entre a Corte e o Parlamento, com a possibilidade de superação da decisão judicial pelo legislativo.

Por meio da chamada "cláusula não obstante" (not-withstanding clause), o parlamento teria o poder de reeditar lei declarada inconstitucional, tornando-a imune ao controle judicial de constitucionalidade pelo prazo de 5 anos, prazo este que poderia ser prorrogado.

Note-se que, no Canadá, necessariamente dentro do prazo de 5 anos haverá novas eleições. Deste modo, a população terá a chance de manifestar através do voto a sua insatisfação com o parlamento por ter se valido da "cláusula não obstante" e eleger 
parlamentares que se comprometam com a não prorrogação do prazo, fazendo valer a decisão do judiciário.

Este modelo também ficou conhecido como "controle fraco de constitucionalidade", em oposição ao modelo de "controle forte de constitucionalidade" existente, por exemplo, nos Estados Unidos e no Brasil.

A partir dessa inovação da Constituição canadense, Peter Hogg e Alison Bushell escreveram artigo (HOGG e BUSHELL, 1997) em que utilizaram o termo "diálogo" para se referir ao fenômeno que surgiu após a vigência da lei máxima daquele país. Segundo o levantamento empírico de Hogg e Bushell, na maioria das vezes, após as declarações de inconstitucionalidade do judiciário canadense, as respostas legislativas, além de imediatas, sempre levaram em consideração com seriedade os argumentos levantados pelo poder judiciário.

Observaram-se diversos tipos de "sequências legislativas", desde a aprovação de novas leis encampando as objeções feitas pela Corte, uma aquiescência do Legislativo relativamente à decisão da Corte, entre outras respostas às decisões da corte constitucional canadense. Além disso, a pesquisa informa que, em regra, as respostas legislativas foram imediatas, que os legisladores procuraram aproximação aos termos utilizados na constituição e que o diálogo foi estimulado mesmo quanto a Corte não declarou a inconstitucionalidade da lei examinada. Hogg e Bushell concluíram que, no Canadá, a regra é o diálogo.

Saliente-se que a tese dos diálogos institucionais recebeu diversas críticas. Carissima Mathen (MATHEN, 2007), por exemplo, destaca que, ao fim, o Legislativo sempre poderia lançar mão da cláusula "não obstante" e superar o entendimento do judiciário. Assim, o termo "diálogo" foi invocado apenas para aliviar ("soften") a realidade: no sistema canadense, ocorre uma supremacia do poder legislativo. Aileen Kavanagh (KAVANAGH, 2016) chega ao ponto de defender que se abandone o termo "diálogo" para se referir ao sistema canadense.

De outro lado, Rainer Knopff (KNOPFF, 1999) afirma que a lógica binária das decisões judiciais tende a gerar a sensação de vitoriosos e derrotados, levando a uma maior polarização entre os extremos. A decisão oriunda do poder legislativo, por outro lado, seria recomendável em razão de sua maior capacidade de conciliar interesses e de encontrar a moderação e estabelecer compromissos.

Conforme anota Rodrigo Brandão (BRANDÃO, 2017, p. 339), há ainda corrente que vai além dos diálogos institucionais, chamada "teoria da construção coordenada", que sustenta que cada "poder" tem a possibilidade de interpretar a Constituição, como pressuposto necessário ao exercício das suas atribuições. A consequência prática dessa abordagem varia, 
mas há vertente que defende até mesmo a não vinculação dos poderes que não concordem com a decisão judicial (PAULSEN, 2002). Para os fins deste trabalho, embora se foque nos diálogos institucionais, diversas considerações dos teóricos da construção coordenada servem de reforço argumentativo para o que aqui se defende, pois, como bem anota Rodrigo Brandão em relação a vertente determinada desta teoria (BRANDÃO, 2017, p. 340):

A construção coordenada, assim como a teoria dos diálogos constitucionais, reconhece a interpretação constitucional como um processo longo e interativo no qual as instituições contribuem com as suas capacidades específicas e atuam com vistas à mútua acomodação das suas perspectivas.

A aplicação dos diálogos institucionais ao âmbito internacional depende menos de algo análogo à "cláusula não obstante" e mais da postura tanto das cortes quanto dos Estados. $\mathrm{Na}$ prática, o fato é que os Estados condenados pelas cortes de direitos humanos podem simplesmente ignorar a sentença, como frequentemente ocorre no sistema interamericano, lamentavelmente. Este poder de fato já serviria como algo análogo à cláusula não obstante. Porém, no caso internacional não se observou o surgimento espontâneo de diálogo na maioria dos casos.

Um exemplo emblemático desta inobservância da sentença internacional ocorreu no caso Gomes Lund e outros versus Brasil. O referido caso tratou da inércia do Estado brasileiro em solucionar os "desaparecimentos forçados" ocorridos durante a ditadura militar, mais especificamente sobre a chamada "guerrilha do Araguaia". Como explica Marcos Augusto Maliska sobre a decisão da Corte Interamericana no caso Gomes Lund e o desenrolar da questão no Supremo Tribunal Federal:

No mérito, manifestou a Corte no sentido de que as disposições da Lei de Anistia brasileira que impedem a investigação e sanção de graves violações de direitos humanos são incompatíveis com a Convenção Americana, carecem de efeitos jurídicos e não podem seguir representando um obstáculo para a investigação dos fatos do presente caso, nem para a identificação e punição dos responsáveis, e tampouco podem ter igual ou semelhante impacto a respeito de outros casos de graves violações de direitos humanos consagrados na Convenção Americana ocorridos no Brasil. Igualmente dispôs que o Estado deve conduzir eficazmente, perante a jurisdição nacional ordinária, a investigação penal dos fatos do presente caso a fim de esclarecê-los, determinar as correspondentes responsabilidades penais e aplicar efetivamente as sanções e consequências que a lei preveja, em conformidade com o estabelecido na Sentença da Corte. Por sua vez, o Supremo Tribunal Federal, na decisão da Arguição de Descumprimento de Preceito Fundamental N. 153, entendeu que a Lei de Anistia, ao ter sido reafirmada pela Emenda Constitucional N. 26, de 27 de Novembro de 1985, verdadeiro ato do Poder Constituinte Originário que instalou, nos termos do seu art. 1, a Assembleia Nacional Constituinte, integrou a Anistia da Lei de 1979 à nova ordem constitucional, não cabendo mais eventual questionamento sobre o recebimento ou não da Lei pela Constituição de 1988. Tem-se, desta forma, clara divergência entre o entendimento da Corte e o entendimento do STF, pois enquanto a Corte afirma que 
as disposições da Lei de Anistia brasileira que impedem a investigação e sanção de graves violações de direitos humanos são incompatíveis com a Convenção Americana, o STF sustenta que a anistia integra a ordem constitucional de $1988 \mathrm{em}$ razão de constar do seu ato constituinte originário. (MALISKA, 2015, pp. 477-478)

O que acabou acontecendo é que o chefe do Estado brasileiro, mesmo que desejasse seguir a decisão da Corte Interamericana, encontrou obstáculo jurídico intransponível dentro da normalidade institucional. Constatou-se o descumprimento da sentença da Corte e o impasse permanece sem solução.

Ilustrado o descumprimento da decisão da Corte, retoma-se a explicação da aplicação analógica dos diálogos institucionais no âmbito internacional. Não há dúvida que incumbe aos Estados soberanos interpretar e aplicar os tratados de direitos humanos sem a necessária intervenção das Cortes Internacionais, do mesmo modo que incumbe ao executivo e ao legislativo interpretar e aplicar a Constituição no âmbito interno. Na hipótese excepcional de não cumprimento da norma é que caberá a intervenção do judiciário, mas isso não significa que os demais poderes ou os Estados soberanos estão dispensados de buscar se portar de acordo com as respectivas normas antes da ordem direta da corte.

Por outro lado, no âmbito internacional os Estados soberanos detém o poder legislativo: através do firmamento de tratados, principal fonte de direito internacional, os Estados soberanos criam normas que os vinculam, numa espécie de "democracia direta" - o próprio Estado, sujeito de direito internacional, em conjunto com outro ou outros estados, delibera sobre as normas que o vinculará.

Sendo que aos Estados soberanos cumpre dar efetiva aplicabilidade das normas internacionais deliberadas em seus respectivos territórios, também é possível dizer que no âmbito internacional os Estados detém ao menos parte do poder executivo. Pode-se dizer também que outra parte desse poder executivo está nas mãos de organismos supranacionais, mas essa discussão foge ao escopo do presente trabalho.

Nessa perspectiva, sob uma analogia com o que ocorre no âmbito interno e partindo da tripartição de poderes proposta por Montesquieu, é possível asseverar que, de certa forma, os Estados soberanos exercem tanto poder legislativo quanto executivo no âmbito internacional, enquanto as cortes internacionais seriam uma espécie de judiciário internacional.

Atualmente parece não haver dúvida que as cortes internacionais efetivamente exercem jurisdição internacional, sendo certo que até se fala em "ativismo judicial" e “autocontenção" na atuação das cortes internacionais (PAZARTZIS, 2013).

Pode-se dizer que a atuação das cortes internacionais de direitos humanos seria a realização de uma espécie de judicial review que tem por paradigma, ao invés da 
Constituição, os tratados internacionais de direitos humanos e por objeto a atuação do Estado soberano como um todo, inclusive do poder judiciário local.

Dentro desta analogia, é importante salientar que a possibilidade de o poder executivo simplesmente ignorar um comando do poder judiciário não é nenhuma novidade na doutrina tradicional. Como expõe Ian Shapiro, se o poder executivo escolher não seguir uma ordem judicial, não há nada que a corte possa fazer a respeito (SHAPIRO, 2002).

Talvez no âmbito internacional este problema seja mais pronunciado por duas razões: primeiramente, o fato de o poder legislativo e executivo se concentrar nas mãos do Estado soberano enfraquece sensivelmente o mecanismo de freios e contrapesos existente no âmbito interno; segundo, sempre existe, na prática, a possibilidade do Estado soberano decidir simplesmente denunciar o tratado que dá poderes à Corte Internacional, apesar de toda a construção teórica que se faz em sentido contrário a esse respeito.

Explicado o conceito de diálogos institucionais e estabelecida a analogia entre o plano internacional e o plano doméstico, a questão que aqui se coloca é sobre a possibilidade de diálogos institucionais entre o "judiciário internacional" (cortes internacionais, sobretudo as de direitos humanos) e o "executivo/legislativo internacional" (Estados soberanos).

Essa abordagem dialógica se prestaria, principalmente, para tentar resolver dois problemas. O primeiro é a baixa taxa de compliance das decisões das cortes de direitos humanos, sobretudo a Corte Interamericana de Direitos Humanos. O segundo é o que se convencionou chamar de "imperialismo dos direitos humanos".

Há que se ter muito cuidado quando se fala em "imperialismo dos direitos humanos" para não desbordar em indesejado relativismo cultural, o que acabaria por inviabilizar uma efetiva proteção internacional dos direitos humanos. Contudo, é pertinente a crítica de Marcelo Neves quando analisa o atual estágio de proteção dos direitos humanos na esfera internacional.

Assevera Marcelo Neves que há uma hiperpolitização da proteção internacional, que, sendo casuística, não corresponde às exigências de um modelo jurídico generalizado em termo de "rule of law". Nesse contexto, o direito fica subordinado diretamente ao poder (NEVES, 2009, p. 95). A citada expressão "imperialismo dos direitos humanos" é mencionada pelo autor. $\mathrm{O}$ diálogo proposto serviria para mitigar este problema, na medida em que a solução para o problema de direitos humanos não seria imposta de fora para dentro, mas seria construída em conjunto.

Retomando à questão do compliance, é intuitivo que os Estados soberanos cumpririam com mais frequência soluções que eles mesmos ajudaram a construir. O diálogo também 
proporciona a exposição de algum problema interno na adoção da determinação da corte internacional, permitindo que se contorne a legislação interna ou os problemas levantados pelo judiciário local, construindo via alternativa para o cumprimento do compromisso internacional.

A ideia da necessidade de relações de cooperação com as Cortes Internacionais é defendida por renomada doutrina. Udo di Fabio, conforme citado por Marcos Augusto Maliska (MALISKA, 2015, p. 473), defende a necessidade destas relações entre os mais altos tribunais nacionais e os tribunais internacionais. Também lembrado por Maliska, Marcelo Neves sustenta que a abertura da estatalidade trouxe consigo uma interpenetração entre ordem estatal e internacional que exige progressivamente um aprendizado e um intercâmbio nas duas perspectivas.

É nessa linha que se defende o diálogo, de maneira análoga ao que ocorre entre os poderes no plano interno. De maneira parecida, Aruna Sathanapally (SATHANAPALLY, 2012 , p. 3) chama de "open remedies" (remédios abertos) mecanismos pelos quais uma corte comunica a sua conclusão de que direitos humanos foram violados, mas, ao invés de expedir uma ordem executiva ou declarar inválida determinada legislação, convida-se outros ramos do governo para decidir como resolver o problema de direitos humanos apontado. Um exemplo seria a declaração de incompatibilidade (declaration of incompatibility - DOI), prevista no Human Rights Act do Reino Unido.

Sathanapally defende a adoção desses "remédios abertos" na adjudicação de Direitos Humanos. A noção de "remédios abertos" parece similar ao que foi denominado de diálogo institucional - ou por outra, o diálogo institucional poderia ser classificado como uma espécie do gênero "remédio aberto" -, de modo que a hipótese do presente trabalho não é de todo pioneira.

Salienta-se, por fim, que no caso internacional a existência de uma "cláusula não obstante" é desnecessária para a ocorrência dos diálogos institucionais. Como asseverado, as Cortes internacionais estão em posição de relativa fragilidade para dar execução às suas sentenças sem a cooperação dos Estados soberanos. Este fato, por si, tende a reclamar postura mais dialógica das Cortes para dar efetivo cumprimento às suas decisões.

No presente tópico, analisou-se de maneira sintética o que se entende por "diálogos institucionais", explorando-se tanto a viabilidade da sua aplicação analógica para a relação analógica entre Cortes Internacionais e Estados soberanos quanto a sua potencial utilidade. A conclusão parcial é que, apesar das críticas, (1) no plano interno a postura dialógica gera uma convivência mais harmoniosa entre os poderes, que passam a buscar soluções construídas em 
conjunto para atender aos ditames constitucionais; e (2) a aplicação analógica dos diálogos institucionais no plano da proteção internacional dos direitos humanos é, em tese, possível.

\section{POSSIBILIDADES DE DIÁLOGOS INSTITUCIONAIS ENTRE CORTES INTERNACIONAIS E NAÇÕES SOBERANAS}

Nesse tópico a abordagem pretendida é a análise de algumas hipóteses que possibilitam a concretização dos diálogos institucionais no campo da proteção internacional de direitos humanos.

Deve-se afastar, de início, o artigo 48.1.f da Convenção Interamericana de Direitos Humanos dos mecanismos estudados mais a fundo no presente tópico. O mencionado artigo possibilita a solução amistosa de violações de direitos humanos entre as partes envolvidas pela Comissão Interamericana. Neste caso, o diálogo propriamente dito se dará entre as partes interessadas, com uma espécie de mediação pela Comissão, e não pela Corte.

Não há dúvida que o mecanismo em questão se aproxima da ideia geral do que aqui se estuda, na medida em que se busca uma solução dialogada e não impositiva. Entretanto, a eventual participação do Estado soberano será enquanto parte do processo, não como efetivo executor da sentença da Corte, o que não se mostra adequado ao conceito de diálogo institucional exposto no presente artigo. Ademais, a Corte Interamericana não participa dessa solução consensual, mas apenas a Comissão Interamericana, não se podendo falar em qualquer diálogo efetivo entre a Corte e o Estado soberano.

Mesmo assim, é interessante perceber, como anotam Cecília Medina Quiroga e Cláudio Nash Rojas (MEDINA QUIROGA e NASH ROJAS, p. 72), que esta espécie de solução - dialogada, repita-se, ainda que não se trate de diálogo entre Corte e Estado -, que inclui o Estado na elaboração de uma solução para as violações, fez com que alguns Estados demonstrassem maior abertura para solucionar os problemas de direitos humanos, ao invés de ignorá-los.

Superado este ponto, cogita-se a aplicação de três institutos já existentes nos sistemas de proteção de direitos humanos como espécie de "catalisador" dos diálogos entre cortes internacionais e Estados soberanos: A sentença de natureza declaratória do sistema europeu, a "teoria da margem de apreciação" e as opiniões consultivas da corte interamericana.

Ruth Ginsburg, conforme citada por Ian Shapiro (SHAPIRO, 2002, p. 68), entende que no plano interno o papel de uma Corte Constitucional é proclamar que determinado 
arranjo legal não é aceitável sob o prisma da Constituição, deixando ao encargo do legislativo desenvolver remédios aceitáveis para a inconstitucionalidade apontada. Comentando a forma da decisão da Suprema Corte no caso Roe v. Wade, Ginsburg observa criticamente que a corte "não convidou nenhum diálogo com os legisladores".

No campo da adjudicação dos direitos humanos perante cortes internacionais, verificase que no sistema europeu já existe mecanismo que funciona de maneira bastante similar ao que defende Ginsburg no plano interno.

Diversamente do sistema interamericano, onde a sentença da Corte Interamericana tem caráter condenatório, ou seja, não só imputa a responsabilidade internacional do Estado denunciado, como também determina como o Estado deverá reparar os direitos violados, no sistema europeu a sentença da Corte tem caráter declaratório. Em outras palavras, a Corte Europeia de Direitos Humanos se limita a declarar a violação de direito humano, deixando a tarefa de reparação aos órgãos nacionais (BICALHO, 2011).

Essa postura é análoga à postura que Ginsburg entende correta no caso da relação entre a Corte Constitucional e os demais poderes no plano interno. Esse tipo de postura pode significar um verdadeiro convite ao diálogo da Corte ao Estado que se encontra em violação de direitos humanos, na linha do que defende Aruna Sathanapally, sobretudo se o sistema possuir órgão encarregado do acompanhamento da execução da sentença internacional, como ocorre no caso europeu (FIX-ZAMUDIO, 2000, p. 220).

Certamente a adoção da natureza declaratória da sentença da corte internacional pode servir de catalisador ao diálogo institucional no plano internacional. Resta saber se este diálogo resultaria em maior observância das sentenças internacionais ou se seria utilizado por Estados violadores de direitos humanos como ferramenta para procrastinar o cumprimento da sentença.

Não é possível estabelecer uma correlação, mas a literatura especializada (HAWKINS e JACOBY, 2008, p. 45) ${ }^{108}$ sugere que as taxas de compliance no sistema europeu - que adota as sentenças declaratórias - são muito maiores que as taxas correspondentes observadas no sistema interamericano.

\footnotetext{
${ }^{108}$ Destaque-se que os próprios autores discordam do que chamam de conventional wisdom, apontando algumas evidências iniciais de que a taxa de compliance na Europa e nas Américas pode ser diversa do que tradicionalmente se defende. Cite-se, ainda, Posner e Yoo, que estimam em 64\% a taxa europeia de compliance (POSNER, Eric A.; YOO, John C. A Theory of International Adjudication; John M. Olin Law \& Economics Research Paper Series Working Paper n. ${ }^{\circ} .206$ and Public Law and Legal Theory Research Paper Series Research Paper n. ${ }^{\circ}$ 146. p. 57) e suspeitam que a taxa de compliance nas Américas é de cerca de 5\% (POSNER, Eric; YOO, John. 2005. Judicial independence in international tribunals. California Law Review 93 (1):3-72)
} 
Desde logo é importante assinalar que essa diferença nas taxas de compliance pode ser resultado de diversos fatores não relacionados com a natureza declaratória ou condenatória da sentença nos dois sistemas. A título de exemplo, pode-se cogitar que a diferença ocorre pelo maior desenvolvimento sócio-econômico dos Estados integrantes do sistema europeu, pela inegável influência do pensamento eurocêntrico na determinação dos próprios direitos humanos, por diferenças culturais, pela fundação anterior da Corte Europeia, pela existência no sistema europeu de órgão encarregado de acompanhar a execução da sentença, por uma conjugação dos fatores citados e por tantos outros fatores não citados.

Uma hipótese que merece destaque, porque diretamente relacionada aos tipos de sentença adotados no sistema interamericano e europeu, é que a taxa de compliance no sistema europeu é maior porque é simplesmente mais fácil dar cumprimento a uma sentença declaratória, que deixa ampla margem de discricionariedade ao Estado, que a uma sentença condenatória.

Contudo, se não se pode afirmar que a taxa de compliance do sistema europeu tem relação necessária com a adoção da sentença com natureza declaratória e do resultante diálogo entre Corte e Estado, também não se pode descartar, a priori, que este fator tenha algum tipo de influência.

Conforme afirmado alhures, é intuitivo que os Estados soberanos se mostrem mais inclinados a implementar solução que eles mesmos ajudaram a construir em diálogo com a Corte internacional, em comparação com solução imposta pela Corte sem levar em conta as peculiaridades do direito interno. A abertura da Corte ao diálogo pode gerar soluções alternativas para os problemas enfrentados, de implementação mais fácil, sem que esta facilitação implique necessariamente num enfraquecimento da proteção aos direitos humanos.

Passando a uma segunda hipótese de mecanismo existente que poderia servir de catalisador ao diálogo institucional internacional, também seria possível cogitar no sistema europeu que a chamada "teoria da margem de apreciação" poderia servir a este fim. Conforme explica André de Carvalho Ramos (RAMOS, 2016), a teoria da margem de apreciação ("margin of appreciation") é baseada na subsidiariedade da jurisdição internacional e prega que algumas questões polêmicas devem ser discutidas e dirimidas pelas comunidades nacionais, não podendo o juiz internacional apreciá-las.

Partindo dessa definição, não é o caso de enquadrar a "margem de apreciação" como um convite ao diálogo entre Corte Internacional e Estado Soberano. Na verdade, a aplicação da teoria da margem de apreciação é uma deferência da Corte Internacional ao 
posicionamento do Estado Soberano, em que a Corte se curva ao Estado por entender que se trata de assunto interno, não cabendo que a Corte venha a se imiscuir.

Essa postura de deferência das cortes mais se assemelha à autocontenção judicial. Autocontenção judicial não é diálogo. Conforme se assevera no decorrer deste trabalho, o que aqui se entende como diálogo é a construção conjunta de soluções entre corte e Estado. $\mathrm{Na}$ medida em que, ao aplicar a margem de apreciação, a Corte internacional deixa o tratamento do problema ajuizado inteiramente nas mãos do Estado, não se pode falar em diálogo. Portanto, a teoria da margem de apreciação não é um meio adequado para deflagrar o diálogo entre corte e Estado.

Por fim, cabe aqui analisar se as opiniões consultivas da Corte Interamericana de Direitos Humanos seriam ferramentas adequadas para estimular o diálogo entre cortes e Estados soberanos. Embora a Corte Europeia de Direitos Humanos também tenha competência consultiva, esta competência é bem restrita e, principalmente, os Estados não são partes aptas a requererem a opinião (JAYME, 2005, p. 106). Já no caso do sistema interamericano, a competência consultiva da Corte é ampla e a opinião consultiva pode ser requerida pelos Estados.

A competência consultiva da Corte Interamericana de Direitos Humanos é prevista no art. 64 da Convenção Americana de Direitos Humanos e no art. $2^{\circ}$ do Estatuto da Corte Interamericana de Direitos Humanos, e tem características únicas, dada a sua amplitude.

Os Estados podem solicitar a opinião consultiva à Corte, que analisa a hipótese apresentada e oferece a interpretação do caso à luz da Convenção Americana. A partir daí, os Estados devem adotar as medidas que entenderem cabíveis para se adequarem à interpretação da Convenção Americana emanada da Corte.

Diante disso, é cabível a indagação se não se está diante de um início de diálogo entre o Estado e a Corte. Afinal, a opinião consultiva não tem, a princípio, a mesma força vinculante que uma sentença de um caso contencioso. O Estado soberano tem, assim, a possibilidade de abordar a questão de direitos humanos tratada na opinião consultiva de diversos modos, havendo certa margem de discricionariedade.

O que se tem aqui não é propriamente a construção de soluções conjuntas para problemas de direitos humanos. A Corte se limita a oferecer seu parecer sobre o caso e o Estado, a partir daí, deverá por conta própria resolver a situação. Por outro lado, é certo que as "sequências legislativas" mencionadas por Hogg e Bushell no artigo que cunhou o termo "diálogos institucionais" não se tratam de interações prolongadas entre poder judiciário e 
poder legislativo. Simplesmente tinha-se uma reação legislativa que buscava enfrentar o problema constitucional apontado em uma decisão judicial.

Sendo assim, por fidelidade ao termo originalmente cunhado por Hogg e Bushell, não há como simplesmente descartar a interação que ocorre entre Estado e Corte numa opinião consultiva como exemplo de diálogo institucional. O que se deve fazer é apontar que esta interação, apesar de exemplo de diálogo, está muito aquém do ideal.

A defesa de diálogo entre Corte e Estado soberano envolve, idealmente, sucessivas interações, correção de rumos, exposições de dificuldades na implantação para que se encontre uma solução de fato conjuntamente construída. Não é isso que se verifica no caso das opiniões consultivas.

No presente tópico, realizou-se a análise de três mecanismos já existentes nos sistemas regionais de proteção aos direitos humanos a partir da possibilidade destes mecanismos induzirem o diálogo entre Estado soberano e corte internacional. A conclusão parcial é que (i) a adoção da "teoria da margem de apreciação" é ferramenta inadequada para induzir os diálogos institucionais; (ii) a sentença declaratória do sistema europeu, caso seja monitorada a sua implementação pelo Estado após a prolação, tem potencial para induzir o desejado diálogo entre corte e Estado; e (iii) as opiniões consultivas do sistema interamericano, adotando-se a concepção estreita de diálogo defendida por Hogg e Bushell, também podem ser consideradas como uma via para o diálogo, mas as interações entre Estado e corte neste caso estão aquém do que se considera como ideal.

\section{CONSIDERAÇÕES FINAIS}

O presente trabalho pretendeu traçar as linhas iniciais de uma possível nova abordagem para a relação entre cortes internacionais e nações soberanas. Inicialmente se abordou o mecanismo de diálogos institucionais verificado no Canadá e a sua possível aplicabilidade, por analogia, à relação entre cortes internacionais e Estados soberanos.

Já num segundo momento, procurou-se abordar possíveis mecanismos nos sistemas internacionais de proteção aos direitos humanos que pudessem propiciar esse diálogo entre as cortes e os Estados.

Essa segunda análise não pretendeu esgotar as hipóteses existentes de mecanismos que podem catalisar o diálogo no âmbito internacional. Certamente há mais possibilidades dentro dos mecanismos existentes que não foram abordadas, para não mencionar a infinidade de 
possibilidades de diálogo em mecanismos que ainda podem vir a ser criados. Reitera-se, aqui se pretendia apenas traçar linhas iniciais em um sentido que pode ser mais produtivo para todas as partes envolvidas.

A via para uma efetiva integração supranacional, que não resulte na mera dominação das nações com reduzido poderio econômico e bélico, será pavimentada pelo diálogo. Todos os ramos do direito têm se aberto para as soluções consensuais, mesmo aqueles ramos tradicionalmente mais refratários a esta ideia, como o direito administrativo. Não há razão para ser diferente com o direito internacional dos direitos humanos.

Como bem anotam Clèmerson Merlin Clève e Bruno Menezes Lorenzetto, em lição plenamente aplicável à posição ora defendida, a "busca por soluções de casos complexos, os quais demandam respostas institucionais elaboradas, precisa ser estabelecida de modo dialógico, como uma conversa contínua entre as partes envolvidas na sua confecção e na sua fiscalização posterior.” (CLÈVE e LORENZETTO, 2015)

Soluções construídas a partir do diálogo tendem a ser mais simples de serem cumpridas, gerando uma taxa de compliance superior. Por outro lado, se o diálogo institucional se apresenta como uma espécie de "meio-termo" entre ativismo judicial e autocontenção no âmbito doméstico, no âmbito internacional essa abordagem também tem potencial para, de um lado, dar efetivo cumprimento aos direitos humanos e, de outro, respeitar a pluralidade dos povos e as suas autonomias, sem incorrer em indesejado relativismo cultural.

É verdade que encontrar esse balanço não se mostra uma tarefa simples. Também é verdade que o diálogo não é uma panaceia que resolverá todos os males da adjudicação internacional dos direitos humanos. A tentativa de implementação dessa ideia, contudo, pode ser um passo na direção certa.

Como demonstrou o caso Gomes Lund e outros (Guerrilha do Araguaia), na prática sempre existe a possibilidade do Estado soberano descumprir a decisão da corte internacional. Se for um Estado com relativa importância econômica e/ou bélica, há muito pouco que se possa fazer para obrigar o cumprimento. Apenas se se tratar de um Estado com pouca força no cenário internacional é que a ameaça de sanções vindas dos Estados mais fortes poderia gerar relativa eficácia da decisão, cabendo a crítica de que se trata de "imperialismo dos direitos humanos".

É preciso lembrar que os Estados soberanos podem enfrentar uma série de dificuldades jurídicas, políticas e econômicas para implantar as sentenças internacionais no âmbito doméstico. De outro lado, não é exigível dos juízes das Cortes internacionais que conheçam 
peculiaridades dos sistemas jurídicos locais ou atual situação política e econômica de todos os países sobre os quais exercem jurisdição internacional.

Nessa linha, a solução dialogada pode conduzir a uma viabilidade da implementação da sentença que não ocorreria de outro modo: Estado e Corte, em verdadeira solução conjunta, traçariam plano de execução da sentença que contornaria as dificuldades enfrentadas pelo Estado naquele caso.

Saliente-se que o que se está defendendo não é uma transigência com os direitos humanos, mas sim a tentativa de se encontrar métodos alternativos para chegar ao mesmo resultado protetivo. A efetividade da jurisdição internacional é um requisito necessário para se atingir uma adequada integração supranacional, e a via do diálogo se mostra como uma abordagem interessante para auxiliar na consecução deste objetivo.

\section{REFERÊNCIAS}

BICALHO, Luis Felipe. A Análise Comparativa dos Sistemas Regionais de Proteção dos Direitos Humanos - Particularidades Sistêmicas e o Delineamento de uma Racionalidade Conforme. Cadernos da Escola de Direito e Relações Internacionais, Curitiba, 14: 42-64 vol.1, 2011

BRANDÃO, Rodrigo. Supremacia Judicial versus Diálogos Constitucionais: a Quem Cabe a Última Palavra Sobre o Sentido da Constituição? 2 ed. Rio de Janeiro: Lumen Juris, 2017. 440p.

CLÈVE, Clèmerson Merlin; LORENZETTO, Bruno Meneses. Diálogos Institucionais: estrutura e legitimidade. Revista de Investigações Constitucionais, Curitiba, vol. 2, n. 3, p. 183- setembro/dezembro 2015

FIX-ZAMUDIO, Hector. La responsabilidad internacional del Estado en el contexto del Sistema Interamericano de Protección de los Derechos Humanos. Instituto de investigaciones Jurídicas, México, 2000

HABERLE, Peter. Estado Constitucional Cooperativo. Rio de Janeiro: Renovar, 2007

HAWKINS, Darren; JACOBY, Wade. Partial Compliance: A Comparison of the European and Inter-American Courts for Human Rights. Paper prepared for delivery at the 2008 Annual Meeting of the American Political Science Association, Boston, MA, August 28-31, 2008. 
HIRSCHL, Ran. Towards Juristocracy: The Origins and Consequences of the New Constitucionalism. Harvard University Press, 2004

HITTERS, Juan Carlos. Control de Constitucionalidad y Control de Convencionalidad: Comparación (Criterios fijados por la Corte Interamericana de Derechos Humanos). Estudios Constitucionales, Santiago, Año 7, no 2, 2009, pp. 109-128

HOGG, Peter W.; BUSHELL, Alison A. The charter dialogue between courts and legislatures (or perhaps the charter of rights isn't such a bad thing after all). Osgoode Hall Law Journal, 35,1997

KAVANAGH, Aileen. The Lure and the Limits of Dialogue. University of Toronto Law Journal, Volume 66, Number 1, Winter 2016, pp. 83-120.

JAYME, Fernando G. Direitos Humanos e sua Efetivação pela Corte Interamericana de Direitos Humanos. Belo Horizonte: Del Rey, 2005

KNOPFF, Rainer. Courts don’t make good compromises. Policy Options, April 1999

MALISKA, Marcos Augusto. Estado e Século XXI: a integração supranacional sob a ótica do Direito Constitucional. Rio de Janeiro: Renovar, 2006

MALISKA, Marcos Augusto. Os Desafios do Estado Moderno. Federalismo e Integração Regional. Curitiba/Munique, 2003. Tese de Doutorado. Programa de Doutorado em Direito da Universidade Federal do Paraná (estágio de doutoramento na Ludwig Maximilian Universitat)

MALISKA, Marcos Augusto. A proteção dos direitos humanos no âmbito de jurisdições concorrentes: o caso da Corte Interamericana de Direitos Humanos e do Supremo Tribunal Federal do Brasil. In MAZZUOLI, Valério de Oliveira e GOMES, Eduardo Biacchi. Direito da Integração Regional. Diálogo entre jurisdições na América Latina. São Paulo: Saraiva, 2015, p. 465-481

MATHEN, Carissima. Dialogue Theory, Judicial Review, and Judicial Supremacy: a Comment on "charter dialogue revisited". Osgoode Hall Law Journal, v. 45, n. 1, 2007

MEDINA QUIROGA, Cecília; NASH ROJAS, Claudio. Sistema Interamericano de Derechos Humanos. Introducción a sus Mecanismos de Protección. Centro de Derechos Humanos: Santiago. 
NEVES, Marcelo. Transconstitucionalismo. São Paulo: Martins Fontes, 2009.

PAZARTZIS, Photini. Judicial Activism and Judicial Self-Restraint: The PCIJ's Lotus Case. In FITZMAURICE, Malgosia; TAMS, Christian J. Legacies of the Permanent Court of International Justice. Leiden (Holanda): Martinus Nijhoff Publishers, 2013. pp. 319-335

PAULSEN, Michael Stokes. The Irrepressible Myth of Marbury. In: Michigan Law Review, 2002-2003

PIGNATARO DE OLIVEIRA, Diogo. Aplicação das Sentenças de Cortes Internacionais no Brasil: A Busca pela Efetividade das Decisões da Corte Interamericana de Direitos Humanos. Revista Constituição e Garantia de Direitos, v. 4, n. 2, 2013.

POSNER, Eric A.; YOO, John C. A Theory of International Adjudication; John M. Olin Law \& Economics Research Paper Series Working Paper n. ${ }^{\circ} 206$ and Public Law and Legal Theory Research Paper Series Research Paper n. ${ }^{\circ} 146$.

POSNER, Eric; YOO, John. Judicial independence in international tribunals. California Law Review 93 (1):3-72. 2005

RAMOS, André de Carvalho. Teoria Geral dos Direitos Humanos na Ordem Internacional. $6^{\mathrm{a}}$ ed. São Paulo: Saraiva, 2016

RAWLS, John. O Direito dos Povos, Seguido de "A ideia de razão pública revista" São Paulo: Martins Fontes, 2014.

RODRIGUES, Tecio de Aguiar. A efetividade das decisões da Corte Interamericana de Direitos Humanos em relação ao direito à propriedade coletiva de comunidades indígenas e tribais. Monografia - FGV. Rio de Janeiro, 71p, 2014

SATHANAPALLY, Aruna. Beyond Disagreement: Open Remedies in Human Rights Adjudication. Oxford (UK): Oxford University Press, 2012

SHAPIRO, Ian. The State of Democratic Theory. Princeton: Princeton University Press, 2002.

VICTOR, Sérgio Antônio Ferreira. Diálogo Institucional e Controle de Constitucionalidade: Debate Entre o STF e o Congresso Nacional. São Paulo: Saraiva, 2015. 


\title{
ON THE POSSIBILITY OF INSTITUTIONAL DIALOGUES BETWEEN
} INTERNATIONAL HUMAN RIGHTS COURTS AND SOVEREIGN STATES

\begin{abstract}
The present article analyzes the so-called "institutional dialogues" and verifies the possibility of being applied by analogy in the relation between International Courts and Sovereign States. It seeks to identify problems in the international jurisdiction of human rights that could be addressed through dialogue and to identify possibilities for dialogue in the application of mechanisms already existing in regional systems.
\end{abstract}

Keywords: Institutional Dialogues. International human rights law. Supranationality. 